The theory of vision and colour perception

This content has been downloaded from IOPscience. Please scroll down to see the full text. 1909 Trans. Opt. Soc. 1110

(http://iopscience.iop.org/1475-4878/11/1/302)

View the table of contents for this issue, or go to the journal homepage for more

Download details:

IP Address: 170.140.26.180

This content was downloaded on 24/08/2015 at 20:50

Please note that terms and conditions apply. 


\title{
THE THEORY OF VISION AND COLOUR PERCEPTION.
}

\author{
By F. W. Edridge-Green.
}

Lecture delivered on October 21st, 1909.

Mr. President, Ladies and Gentlemen,-I assume that the cones of the retina are insensitive to light, but sensitive to chemical changes in the visual purple. Light falling upon the retina liberates the visual purple from the rods, and it is diffused into the forea and other parts of the rod and cone layer of the retina. The decomposition of the visual purple by light chemically stimulates the ends of the cones (probably through the electricity which is produced), and a risual impulse is set up, which is conveyed through the optic nerve fibres to the brain. I assume that the visual impulses caused by the different rays of light differ in character just as the rays of light differ in wave-length. Then, in the impulse it. self, we have the phrsiological basis of the sensation of light and in the quality of the impulse the phrsiological basis of the sensation of colour. I have assumed that the quality of the impulse is perceived br a special perceptive centre in the brain with the power of perceiving differences possessed by that centre or portions of that centre. According to this view the rods are not concerned with transmitting visual impulses, but only with the risual purple and its diffusion.

I shall now show you some pictures of the rods and cones. The point that you will notice here especially is that the rods and cones 
have absolutely separate functions. In the centre of the eye where we see best only cones are to be found, and we can trace these cones very definitely to the nerve fibres which convey the sensation of light to the brain. But when we come to the rods we find something very different. We find that these rods, each of which contains the risual purple in its outer segment, are very loosely connected with the optic nerve fibres, and instead of one element being connected with a nerve fibre, as we find in the case of the cones, we see that a great number of rods appear to be connected with one nerve fibre.

I must now refer to the beautiful and accurate work of Kühne, who has done so much in connection with the visual purple. $\mathrm{He}$ has been very much misquoted, as will be noticed from the few extracts which I give, I am not aware of one of the facts discovered by him which is inconsistent with the hypothesis I have given; I will even go further and say that they all directly support it. Kühne expressed the opinion that the risual purple could not be essential to vision because it was not present in the cones, but he does not appear to have looked for it between the cones. It seemed to me more probable that the rods should produce a secretion which would affect other cells rather than themselres. In one case Kühne did find the visual purple difiused into the rest of the retina. He writes:- "In one of these eyes which had been laid open in the dark for an hour, I saw to my great surprise the whole of the retinal mass flooded by a clear purple solution, which, when poured upon a plate, exhibited the same behaviour to light as the mass itself." This refers to the retina of a shark.

Kühne's chief objection to the riew that the visual purple is the visual substance-namely. that is not present in the cones-is a necessary requisite of the theory which I have advanced. 
The facts which he has brought forward in supjor't of his other two objections upon examination will be found to support my theory. They are that animals, such as frogs, naturally poscessing the pigment, continue to see when their visual purple has been absolutely bleached, as it inay be by prolonged exposure to strong light, and that the visual purple is entirely wanting in some animals which see very well. Now, as I said, Kühne has been very much misquoted on this point; even by well known physiologists. Physiologist after physiologist has said to me, "But how can the visual purple be the essential substance of vision when it is not present in the daylight at all?" Agrain I will quote Kühne, and you will find there is the very greatest difficulty in getting rid of the purple even in daylight, except by exposing the eyes to direct sunlight, but you can hardly call that a physiological experiment. Kühne writes:- "Without direct sunlight, I have never succeeded in a room in obtaining frogs' retinas free from visual purple, not even when I allowed the animals to leap about before the window the whole day long." He bleached their eyes by exposing them for 20 minutes or half an hour to direct sunlight. I should not like my eyes exposed to direct sunlight for a few minutes. $M$ r contention is that in those cases in which the retinas were bleached by sunlight, and the frogs were still able to see there was sufficient visual purple or its decomposition products for vision, but not enough for external recognition. A very important point is mentioned by Kühne, namely, that after the frog's eyes had been bleached in this way the regeneration of the visual purple was defective. It had permanently injured the animal's eyes. Although it was able to see to get out of the way of the hand, it did not show that the cyes were in a satisfactory state after being exposed. I will again quote Kuhne on the second objection. He supplies me with the argument I use against 
him. "According to all appearances the visual purple in the bird's eye is deficient in proportion as the retina is provided with other more stable means of absorbing coloured light, I mean the coloured globules of the cones. This is at least the case in the nocturnal and predaceous birds, and is entirely true as regards the pigeon and the fowl." It will be seen that this is in favour of my view, the cones having other means of stimulation, the visual purple is not required. Light acting on these cones with their coloured globules caused sufficient stimulation, and the elaborate process, which is at its perfection in man, was not required in order to produce a sensation of vision. Birds having coloured globules had a different mechanism of stimulation. Whether the globules act by absorption or as filters, is not known, but their presence is quite sufficient to explain the absence of rods in these birds. It seemed to me that the photo-chemical processes necessary for vision must have an elaborate nerrous mechanism which could only arise from the retina. The peculiar arrangement of the rods seemed to indicate that these were the elements involved. I will quote Kühne on this point :"It must not be forgotten that the retinal epithelium of the choroid has been proved to be a very important phrsiological or chemical constituent of the retina, or, stated shortly, as a purpurogenous gland, the cells of which can scarcely fail to possess a very peculiar complicated innervation. Now, i do not see that irritalle fibres can arise from any other source than from the nervous mass of the retina." It does not appear to have occurred to Kühne tha: the rods were the nerrous elements for which he was seeking. He looked for some direct connection between the rods and the pigment cells. We know that in other parts of the nervous system it is sufficient to have contact between two cells without direct continuity.

The anatomical arrangement of the retina is 
consistent with the theory I have given. In the forea of the retina only cones are to be found. Immediately external to this each cone is surrounded by a ring of rods. The number of rings of rods round each cone increases as the periphery is reached. The outer segments of the cones are situated in a space which is filled with fluid. The external limiting membrane retains this fluid in its place. So that we have actually in the eye a layer of fluid which is confined definitely by two membranes, and in this fluid there are the ends of the rods containing the visual purple and the ends of the cones, so that the visual purple passes into this fluid. Another very curious and important fact (which puzzled Kühne) was this, "that there are pigmented processes passing by the sides of the segments containing visual purple." These processes, as he thought, were to protect the visual purple, but he could not understand if the rods were to act as a means of conveying a light impulse to the brain why the visual purple should be specially sheathed. But if you take my view, you will understand why it should be protected in the day-time. It is easy to understand how adaptation to darkness is brought about by a steadily increasing percentage of visual purple being added to this fluid, thus rendering it more and more sensitive to light. It is easy to trace the connections of the cones with the inner layers of the retina, but the rod fibres appear to end in nucleated enlatgements. Now I shall mention a few facts which are consistent with this view, and absolutely inconsistent with any other view. The first one is that if the cones of the retina are insensitive to light and sensitive to chemical change in the visual purple, light should be able to fall on the eye without producing any sensation of light-that is to say, the contre of the eye which has not been prepared by visual purple should be blind. This experiment is very easy to make. If the cones are not sensitive to light, a ray of light 
falling upon the fovea alone, and not upon the adjacent portion of the retina containing rods, should produce no sensation of light, provided that there is not already any visual purple in the fovea. It has been known to astronomers for a long time that if a small star in a dark portion of the sky be steadfastly looked at it will disappear from view, whilst other stars seen by indirect vision remain conspicuously visible.

The following quite simple experiment shows the same thing. If a piece of black velvet, about three feet square on a door, have a pin put in the centre, and the source of light be behind the observer, the pin will be brightly illuminated; and on looking at it (the observer not being too close), and keeping the eye quite still, the pin will disappear, the visual substance diffused into the fovea centralis being used up and not renewed. When viewed by indirect vision, it is impossible to make it disappear in this way. When I have taken great care to have rery dark surroundings, and have used only one eye, I have made moderately bright lights disappear in this manner. The greatest difficulty is found with red light, which it is very difficult to make disappear. This, however, we should expect from our knowledge of the visual purple, for red light bleaches it very slowly, and therefore a much longer time would be required before the visual purple already in the fovea was used up. These facts have been attributed to a defective sensibility of the fovea for feeble light. The important point, however, that the light is at first seen most clearly by the fovea and onlysubsequently fades, has been overlooked. If these facts were due to a defective sensibility of the fovea the star nr light would not be visible at first. It is mentioned by Helmholtz, and stated by him to he quite inexplicable that a perceptible interval elapses before we see with our yellow spots after opening our eyes. If, in a dimly lighted room one eye be directed towards a uniformly illuminated surface, then 
on opening the eye the region corresponding to the yellow spot will be seen as an oval black patch, and light appears to invade this patch from without inwards. The fovea centralis is the last point to convey a light sensation.

The lecturer then had thrown on the screen slides showing a table of wave-lengths, a section of the fovea and every part of the eye. Proceeding, he said : I have seen the visual purple in the fovea between the cones. Von $K$ ries has endeavoured to show that the rods have a special function, being concerned with vision at low intensities. The observation upon which he has specially relied is that the recurrent image is not seen in the fovea. The method which he adopts is open to the objection that if the recurrent image were retarded on reaching the foven it would give the same appearance as if it passed it. I have carefully observed this phenomenon, and am quite unable to convince myself that there is anything more than a retardation of the recurrent image at the fovea. Hess holds the same opinion, and describes a simple experiment which appears to be very conclusive. If a thin strip of cardboard be moved backwards and forwards in front of the ere before a dark background, it will be noticed that the recurrent image of the paper will appear to be bent at the position corresponding to the forea.

If we suppose that visual purple is the means by which we see, it is easily reognised that there must be a definite arrangement for adaptation to light, and this probably corresponds to the forward morcment of the processes of the pigment cells which puts them in the most favourable position for renewing and protecting the risual purple, which is used up more rapidly with a bright than with a dull light. If we suppose that in total colour-blindness there is defective light adaptation through an imperfect forward movement of the processes of the pigment cells, wo shall have all the phenomena which are found in these cases. The diminution of visual 
acuity only occurs in light of ordinary intensity, and vision by a feeble light is as good as with normal sighted persons. The photophobia which is found in these cases would necessarily follow from the imperfect action of the pigment cells. Von Tschermak, Hering, Hess, Garten, and others have found only gradual quantitative differences in the sight between the foreal and the extrafoveal area. The Purkinje phenomenon, the alteration of optical white equations by the state of dark adaptation, the colourless interval for spectral lights of increasing intensity, the different phases of the after image, all exist, not only in the extrafoveal, but also, only gradually diminished, in the foveal region. That absolutely disposes of the argument as to the special action of the rods, because every one of the so-called visual purple phenomena have been found in the portion of the retina where there are no rods. In accordance with the theory I have given, we should expect, as these very able men have found, that there would be only a quantitative difference. I entirely. agree with those experiments. I have never been able to find any qualitative difference between the extrafoveal and the foveal regions. I will now speak of the chemical analogy. The visual purple gives a curve which is very similar to that of many other photo-chemical substances. We know that with photo-chemical substances the chemical effect is not proportional to the intensity of the light. That is, a different curve is obtained with weak light from that which is formed with light of greater intensity. It is reasonable, therefore, to suppose that the visual purple which is formed by the pigment cells under the influence of a bright light would be somewhat different in character from that which is formed in darkness. Again, from the chemical analogy which I have just given, even if the risual purple were of the same character we should not expect similar curres with different intensities of light. It is probable that both 
factors are in operation. This deduction gives an explanation of the Purkinje phenomenon, or the fact that when the eyes are adapted to darkness the point of greatest luminosity is shifted more towards the violet end of the spectrum.

The photo-chemical action of a substance corresponds to the absorption curve. The following three curves almost correspond :-(1) the luminosity curve for the threshold of stimulation; (2) the stimulation value for total colourblindness; and (3) the absorption curve of the visual purple. (1) has its maximum at $\lambda 505$, the other two at $\lambda 500$. The centre of pure green is also about 7505 . The neutral point in $\mathrm{di}$ chromic vision is about the same point. Assuming that the visual purple is the visual substance, we get a remarkable correspondence in the figures between the visual purple and the actual facts of vision. These facts bring the visual purple not only into relation with normal sight, but with a disease in which we know there is defective light adaptation. Those dichromics who have shortening of the red end of the spectrum have a luminosity curve which is very similar to that of a normal-sighted person with a spectrum of lesser intensity. We have only to assume in these cases either that the nerrous apparatus is less responsive or that the visual purple formed at one intensity of light is similar to that formed at a lower intensity br a normal-sighted person. If we regard the nervous apparatus as not being easily responsive to the stimulus we shall get an explanation of a number of these cases, even when there is a considerable shortening of the red end of the spectrum by dull light. We also have an explanation of other conditions, such as erythropsia, or red vision, white objects appearing more or less red. If we suppose that the eye has remained in a state of light adaptation, the visual purple produced being more sensitive to the red rays, objects appear of this colour. As we should expect, erythropsia is frequently associated with 
Temeralopia, or difficulty in seeing in the twiJight, the eyes being adapted to light and not to darkness. In green vision the eyes have probably remained in a condition of more or less adaptation to darkness, and are therefore more sensitive to the green rays. Some curious facts follow from this hypothesis; for instance, the after-image of black should be green, not white. When the eye becomes more sensitive to the red and violet ends of the spectrum, the after-image of a white object will be purple instead of black. Mauy of you may have noticed that the afterimage of any colour is in the first instance purple. This fact gives an explanation of a pretty little toy, which excited much interest a few years ago, Benham's top. This consists of two sectors, one white and one black; on the white sector are black lines at intervals and at different distances from the centre. When the top is turned the black lines nearest the black disc appear red, this red being the contrast colour to the green, which is seen as the afterimage of the black dise.

Every acute observer knows how when the sun sets reds become darker and darker until they appear black, whilst blues and greens remain conspicuously visible. It is the same with the after-image of black; in a feeble light it is white, raise the illumination it hecomes yellow, raise it again it becomes rellow-green, increase it further it becomes pure green, try the experiment in the sunlight and it becomes blue-green. The converse occurs when the eye is becoming arlapted to light, the eye becomes more and more sensitive to the red end of the spectrum. Gotch and Waller have both written some very interesting papers on the electrical changes in a irog's retina caused by light. We cannot say what is the exact mechanism, but the electrical effects we have obtained already from the retina are quite sufficient to explain the facts. All that is required is some periodicity in the nerve impulses. We should expect that the physio- 
logical centre of the spectrum would correspond to the maximum of the absorption curve of the visual purple, and we find that this is the case.

The lecturer had thrown on the screen slides showing the spectrum as seen by different people, and showing the different classes and degrees of colour-blindness, also pictures painted by colour-blind people-the tetrachromics, the trichromics, the dichromics, and one who was almost monochromic. Concluding, he said: In the past there is no fact that I have had more difficulty in establishing than the simple fact that if rou isolate a portion of the spectrum it appears monochromatic. These monochromatic regions are very large, an ordinary normal sighted person sees about eighteen of such divisions in the spectrum. The monochromatic region, and its varying size with different persons, I consider to be a fundamental fact of colour vision. Even a small degree of colourblindness greatly reduces the number of divisions. For instance, a man having trichromic vision sees only half the normal number in the spectrum. Though dangerously colour-blind, he would be able to pass the official test for colourblindness with ease. The spectrometer I am showing rou this evening is constructed so that the size of these regions can be ascertained with great accuracy. Only last year a well known phrsicist, who had denied the existence of these monochromatic regions over and over again, came to see them, after I had given an address on Colour Vision in Dublin. He said he could see 12,000 colours in the spectrum; and remarked, "I can tell with the greatest ease the difference in colour between the two D lines." He then sat down to the spectroscope and marked out a monochromatic region in the green, which in size was about one-eighth of the whole spectrum, and a little bigger than normal.

Mr. S. D. Chalmers said there were one or two questions he would like to raise. It seemed to 
him that the one great difficulty associated with all purely absorption theories was the difficulty of accounting for the change from green towards red, on the one hand, and from green towards blue on the other. Either of these changes might be attributed to the diminishing absorption of a single visual substance, but why should the diminishing absorption produce red on the one hand and blue on the other? A possible explanation har occurred to him that the other properties associated with absorption might have an important influence; for example, on approaching an absorption band the reflection would increase, and it seemed possible that a change in the reflection co-officient or in the refractive index of the substance on the two sides of an absorption band might meet this diffculty. Also, one had to take account of a great deal more than absorption effects of the chemical substance. It was necessary to take account of the possibility of electrical currents in local resonating sristems, and one fact seeming to bear this out was that there seemed to be a very loose connection between some of the local nerve circuits and the main transmitting system. In many devices for receiving electrical waves we would note that the resonating system was loosely connected to the main circuit to avoid the disturbance of its free period of resonance. In fact, electrical as well as purely chemico-physical properties might be involved.

$\mathrm{M}_{\text {r. J. S. Dow said that he had listened to }}$ Dr. Edrirlge-Green's lecture with keen interest. All these questions of the structure and behaviour of the retina had a very direct bearing on problems in photometry and illumination, and it was a great help to those connected most closely with the engineering and phrisical sides of the subject, to hear the latest plursiological theories so lucidly explained. He was particularly interested in Dr. Edridge-Green's important statement that risual purple had been found to occur in the forea between the cones, 
and his additional suggestion that the rods were concerned with the regeneration and distribution of visual purple, but did not play a direct part in vision. There were many effects encountered in attempting the comparison of the brightness of sources of light of different colours which could only be explained by the knowledge of the retina; and some physiologists, he understood, had advanced a theory based on the fact that the cones were mainly instrumental in vision at a high illumination, while the rods were the predominant organs when the illumination was very low. Many peculiar effects, such as the Purkinje phenomenon and the fact that at very weak illuminations we could see light but no colour, had been attributed to the struggle for predominance between the two sets of organs. The same theory had been used to explain the fact that a judgment of the relative brightness of two heterochromatic surfaces varied very greatly according to the portion of the retina on which the image of the illuminated surfaces was received. But, according to Dr. Edridge-Green's theory, a different explanation was necessary. Whatever the explanation, however, there seemed to be a sudden change in retinal conditions when a certain order of illumination was reached. According to the speaker's experiments, this abrupt change occurred at about 0.2 meter-candles. When the illumination was reduced heyond this point, for example, the central region of the retina, where there were only cones, seemed to become more or less blind. and there was a sudden fall both in acuteness of vision and in capacity to appreciate changes in light and shade. Perhaps the lecturer could explain why this should be the case. Some work of Professor Burch seemed to fit in with Dr. Edridge-Green's theories regarding the retina very well. Dr. Burch found that, although at very low illuminations one was usually unable to appreciate colour, the faculty was eventually recovered if one rested in complete darkness for 
about two hours. This suggested that the regeneration of the visual purple had an important effect. Mr. Dow added that he appreciated Dr. Edridge-Green's distinction between the different causes of colour-blindness. He had always been impressed by the view that cases of colour-blindness might exist the cause of which was some disturbance of the centre of perception rather than some peculiarity of the retina. Cases described by Dr. Edridge-Green and others, for example, seemed to suggest that loss of colour-perception did not invariably entail a corresponding loss of the power to perceive light.

Dr. Edridge-Greev said one point mentioned had been raised nearly every time he showed the pictures. He could best make it clear by comparing a normal-sighted man with one who saw seven colours in the spectrum. Suppose, for instance, he wished to test supernormal vision with his lantern. He would put in a glass which he knew would correspond exactly to the indigo. It would have its dominant wavelength in that particular portion of the spectrum. Any ordinary sighted person would call it violet, and every time he came to it he would call it violet. In no circumstances, even by accident, would he call it indigo, and if he tried to guess you would know that he was wrong. As a matter of fact, colour-blind people know that if they guess they will be considered incompetent, and they do not think that they are incompetent. They have always seen in that particular way, and they think they have as good sight as anybody else. Then a man who was guessing would easily be detected, as he would no doubt at one time call the colour violet; whereas a man who saw indigo would name it every time and remember it. Regarding the pictures painted by colour-blind people, a man had an unlimited number of colours spread out on the colour palette. He sees a certain colour on the picture (for instance, yellow), and he makes a 
mental note that it is green. Then he looks amongst the paints for a typical green to paint it with, but he would not look at the yellows, which are nondescript colours to him. If I take the most representative colour and say to him, "Won't you take that colour?" he will say, "No, that is a poor sort of colour." Another test for colour-blindness, used in Germany, comprised a number of pencils with coloured challss protruding. These were placed before a man, who picked out the particular colour he thought he should have to use, and in this way many mistakes were made. $\mathrm{He}$ had mentioned that the visual purple had been very carefully examined by Kühne and others. All the facts had been found to agree with visual phenomena. The cones had no visual purple; therefore Kühne and others assumed that visual purple could not be essential to vision, in spite of the fact that it was in every way per. fect for that purpose. The visual purple pheno. mena were found in the centre of the eye, so that any theory of sight had to explain why they were found there. The retina had been examined photo-electrically by Gotch, who found a difference in time relations, the starting interval and the curves were not precisely the same, there was a little difference in the curve all the way up the spectrum.

The lecturer then, in answer to Mr. Dow's question, said that there were three definite processes which had been shown to take place in the retina, and these varied according to the wave-length of the light used. Gotch had shown that there was a latent interval corresponding to the diffusion of the visual purple; the second process corresponded to a photo-chemical change, and the third to a nerrous stimulation. A friend of his, who played golf with him, could pass the ordinary official test, but could scarcely recognise a red flag at a distance equal to the length of that room. It took more stimulation for the visual purple to diffuse into the 
fovea. Where the rods were concentrated they would expect to get the easiest effect, but where the visual purple had to travel some distance they could obviously see that they required a much stronger light. But just as had been mentioned about Burch's experiment, if we only waited long enough we might be able to see with the centre. Von Tschermak, Horing and Hess say that all the phenomena obtained outside the fovea are found in the fovea, showing no qualitative difference between the extra-foreal and the foveal regions. With regard to $\mathbf{M r}$. Chalmers' remarls, there was undoubtedly a great deal more to do ; in fact, when any discovery was made, it opened a number of fresh lines of research. One single substance, the visual purple, by its decomposition caused a sensation of light. 